\title{
Influence of maxillary posterior dentoalveolar discrepancy on angulation of maxillary molars in individuals with skeletal open bite
}

\author{
Luis Ernesto Arriola-Guillén ${ }^{1 *}$, Aron Aliaga-Del Castillo ${ }^{2}$ and Carlos Flores-Mir ${ }^{3}$
}

\begin{abstract}
Background: The aim of this study was to determine the effect of the maxillary posterior dentoalveolar discrepancy (MPDD) on the angulation of maxillary molars in open bite subjects.

Methods: Pre-treatment lateral cephalograms of 90 young adults with skeletal open bite were examined. The sample initially included six groups categorized according to MPDD condition (present or absent) and sagittal skeletal facial growth patterns (classes I, II, or III). Then, the sample was separated into two groups according to MPDD (present $=50$, absent $=40$ ). When the eruption of the maxillary third molar was apparently blocked by the presence of an erupted second molar, a MPDD was considered. Maxillary molar angulation was measured. Independent $T$ test was performed to determine differences between the groups considering MPDD condition. Principal component analysis (PCA) and multivariate analysis (MANCOVA) test were also developed.

Results: A decreased molar angulation was found in all groups with MPDD (overall $p<0.001$, class $1-p<0.001$, class $\|-p<0.001$, and class $I I-p<0.05)$. The maxillary first and second molars angulations were lower between approximately $7^{\circ}$ and $14^{\circ}$ in cases with posterior discrepancy. The PCA was used to reduce the number of initial cephalometric variables; thereafter, a MANCOVA test was applied. Significance was only found for MPDD $(p<0.001)$, APDI $(p=0.001)$, and ratio $\left(A^{\prime} \sigma^{\prime} / A^{\prime} P^{\prime}\right)(p=0.026)$ for maxillary first molar angulation and APDI $(p=0.011)$ and MPDD $(p<0.001)$ for maxillary second molar angulation.
\end{abstract}

Conclusions: The MPDD generates a major mesial displacement of the second and first molar roots with a concurrent simultaneous distal angulation of the associated crowns in individuals with skeletal open bite.

Keywords: Posterior discrepancy, Molar angulation, Open bite, Cephalometry

\section{Background}

The angulation of posterior molars has been studied in several papers [1-4] including individuals with different sagittal malocclusions associated with different sagittal and vertical growth patterns, but none so far has evaluated the specific impact of maxillary posterior dentoalveolar discrepancies (MPDD) (apparent lack of space for erupting third molars by inadequate pathway eruption) on molar

\footnotetext{
* Correspondence: luchoarriola@gmail.com

${ }^{1}$ Division of Orthodontics, Faculty of Dentistry, Universidad Científica del Sur - UCSUR, Calle Los Girasoles \# 194, Dpto. \# 302, Urb. Residencial Los Ingenieros de Valle Hermoso, Santiago de Surco, Lima, Perú Full list of author information is available at the end of the article
}

angulations. It has been suggested that posterior discrepancies may be related to crowding relapse and third molar impaction [5-10]. Nevertheless, the majority of orthodontists and oral surgeons do not consider the preventive third molar extraction in order to prevent anterior crowding [11]. There are a few systematic reviews [12-14] in literature unsupportive on the role of the third molars in the development of late incisal crowding. In addition, it has been shown that a maxillary posterior discrepancy is not necessarily associated with increases in maxillary molar vertical eruption, overbite, or anterior lower facial height [15]. One hypothesis suggests that the posterior discrepancy should have an increase in the mesial angulation of the 
upper first and second molars (involving their crowns and roots) [6-10], while another hypothesis suggests that in MPDD cases, the pressure from the erupting maxillary third molar generates a mesial push over the second molar roots with a concurrent simultaneous distal tipping of their crowns [1].

Because of the existing controversy for either one of the described hypothesis, namely mesialization of posterior molars or a distoangulation of the molar crown with a concomitant mesialization of their roots, the purpose of this study was to determine the effect of the MPDD on the sagittal inclination of maxillary molars in open bite individuals with different sagittal malocclusions. If such associations existed, then this information could be useful for clinicians when treatment planning biomechanical approaches to cases with potential MPDD, especially in subject with skeletal open bite.

\section{Methods}

This retrospective study was approved by the ethical committee of the School of Dentistry, Universidad Científica del Sur, Lima, Perú.

\section{Sample characteristics}

The sample included 90 pre-treatment lateral cephalograms of Latin-American individuals (45 male, 45 female). These cases were part of a previously published [15] sample of cases. All the cephalograms were taken at maximum intercuspidation with the lips at rest in subjects aged 15 to 30 years old $(21.50 \pm 4.48)$. Imaging was performed with a digital cephalometric panoramic equipment (ProMax ${ }^{\circ}$, Planmeca, Finland) with settings set at $16 \mathrm{~mA}$, $72 \mathrm{kV}$, and 9.9 s. Cephalometric analyses were performed digitally by two calibrated examiners with MicroDicom viewer software (version 0.8.1; Simeon Antonov Stoykov, Sofia, Bulgaria), without magnification, at a scale of 1:1.

Subjects with previous orthodontic treatment, tumors, infection or prosthetic molar reconstruction in the maxillary molar region and without maxillary third molars (extracted or missing) or any other missing/extracted permanent teeth were not considered.

Although a convenience sample of available records was used, sample size was calculated to demonstrate external validity. The sample size was calculated considering a mean difference of $10^{\circ}$ in the maxillary second molar sagittal inclination as a clinically relevant difference between groups with and without MPDD. A standard deviation of $4^{\circ}$ was considered (obtained from a preliminary pilot study) with a two-sided significance level of 0.01 and a power of $90 \%$. Although a minimum of five subjects per group was required, at least eight subjects per group were available. The calculated sample was 30 subjects; however, data from 90 subjects that met the selection criteria in a reference center of imaging were included.

\section{Sample grouping}

The study sample included six groups categorized according to their MPDD condition (present or absent) and to their sagittal skeletal facial growth patterns (classes I, II, or III) [16-19] (Table 1).

The definitions of the cephalometric points, distances, and angles [18-22] between them are shown in Table 2.

All subjects had a skeletal open bite (FMP angle greater than $26^{\circ}$, ODI lower than $72^{\circ}$, and lower anterior facial height greater than $67 \mathrm{~mm}$ ) (Table 3).

Therefore, the groups were set as follows:

o Open bite class I group with maxillary posterior discrepancy OBCIG-PD $(n=18)$ : ANB angle between $0^{\circ}$ and $5^{\circ}$, antero posterior dysplasia indicator (APDI) of $81.4^{\circ} \pm 4^{\circ}$, angle class I malocclusion, bilateral class I molar relations, overjet between 1 to $5 \mathrm{~mm}$, negative overbite greater than $0.5 \mathrm{~mm}$, and diagnosed with maxillary posterior discrepancy

o Open bite class I group without maxillary posterior discrepancy (OBCIG-WPD) $(n=10)$ : the same with the OBCIG-PD, but without posterior discrepancy

o Open bite class II group with maxillary posterior discrepancy (OBCIIG-PD) $(n=19)$ : ANB $>5^{\circ}$, APDI $<75^{\circ}$, angle class II- 1 malocclusion, bilateral class II molar relations, overjet greater than $5 \mathrm{~mm}$, negative overbite greater than $0.5 \mathrm{~mm}$, and diagnosed with maxillary posterior discrepancy

o Open bite class II group without maxillary posterior discrepancy (OBCIIG-WPD) $(n=22)$ : the same with the OBCIIG-PD, but without posterior discrepancy

o Open bite class III group with maxillary posterior discrepancy (OBCIIIG-PD) $(n=13)$ : ANB $<0^{\circ}$, APDI $>88^{\circ}$, angle class III malocclusion, bilateral class III molar relations, overjet lower than $-1 \mathrm{~mm}$, negative overbite greater than $0.5 \mathrm{~mm}$, and diagnosed with maxillary posterior discrepancy

Table 1 Sample distribution by group, sex, and age

\begin{tabular}{lllll}
\hline Group & Male & Female & Total & $\begin{array}{l}\text { Age }^{a} \\
\text { Mean (SD) }\end{array}$ \\
\hline OBCIG-PD & 9 & 9 & 18 & $20.40(4.67)$ \\
OBCIG-WPD & 4 & 6 & 10 & $20.87(4.79)$ \\
OBCIIG-PD & 6 & 13 & 19 & $22.64(5.39)$ \\
OBCIIG-WPD & 11 & 11 & 22 & $21.74(4.46)$ \\
OBCIIIG-PD & 8 & 5 & 13 & $20.67(3.83)$ \\
OBCIIIG-WPD & 7 & 1 & 8 & $22.69(3.79)$ \\
Total & 45 & 45 & 90 & \\
\hline
\end{tabular}

${ }^{a}$ Not significant based on independent $T$ test according to posterior discrepancy by groups

OBCIG open bite class I group, OBCIIG open bite class II group, OBCIIIG open bite class III group, $P D$ posterior discrepancy, WPD without posterior discrepancy 
Table 2 Definitions of cephalometric points and angles used in this study

\begin{tabular}{|c|c|}
\hline Angular measurements & Definition \\
\hline SNA & The angle between points sella $(S)$, nasion $(N)$, and subnasal $(A)$ in degrees [16] \\
\hline SNB & The angle between points sella (S), nasion (N), and supra mental (B) in degrees [16] \\
\hline ANB & The angle to assess the skeletal relationship between points A and B in degrees [16] \\
\hline APDI & $\begin{array}{l}\text { The anterior-posterior dysplasia indicator to assess the skeletal relationship and is obtained } \\
\text { from the algebraic sum of the angles N-Pg-FH (facial plane) plus/minus the angle AB-facial } \\
\text { lane (is positive when the point B is ahead of point A and is negative when the point A is } \\
\text { ahead of point B) and plus/minus the angle FH-PP (palatal plane) (is negative when PP is } \\
\text { tilted upward and positive when tilted down) [17] }\end{array}$ \\
\hline FMP & The angle between the porion-orbital line and mandibular line in degrees \\
\hline ODI & $\begin{array}{l}\text { The overbite depth indicator to assess the tendency toward open bite is obtained from the } \\
\text { algebraic sum of the angles AB-MP plus/minus the angle FH-PP (palatal plane) and is negative } \\
\text { when PP is tilted upward and positive when tilted down [18] }\end{array}$ \\
\hline $\begin{array}{l}\text { Maxillary first molar } \\
\text { angulation }\end{array}$ & $\begin{array}{l}\text { The angle formed by the maxillary first molar axis (intercuspid groove-bifurcation) and the palatal } \\
\text { plane (ANS-PNS), represented by a horizontal line }\end{array}$ \\
\hline $\begin{array}{l}\text { Maxillary second molar } \\
\text { angulation }\end{array}$ & $\begin{array}{l}\text { The angle formed by the maxillary second molar axis (intercuspid groove-bifurcation) and the } \\
\text { palatal plane (ANS-PNS), represented by a horizontal line }\end{array}$ \\
\hline Linear measurements & Definition \\
\hline$A^{\prime} P^{\prime}$ & $\begin{array}{l}\text { The distance between the perpendicular extensions of points } A \text { and } P \text { on the palatal plane }\left(A^{\prime} P^{\prime}\right) \\
\text { in millimeters: point } A^{\prime} \text { is the perpendicular projection of point } A \text { to the palatal plane and } \\
\text { point } P^{\prime} \text { is the perpendicular projection of the posterior-most point of the maxillary tuberosity } \\
\text { to the palatal plane }[6,9,19]\end{array}$ \\
\hline$A^{\prime} 6^{\prime}$ & $\begin{array}{l}\text { The distance between } A^{\prime} \text { and } \sigma^{\prime} \text { in millimeters, the anterior maxillary base length is defined by the } \\
\text { measurement between } A^{\prime} \text { and } \sigma^{\prime} \text {. Point } \sigma^{\prime} \text { is the perpendicular projection of the anterior-most point on } \\
\text { the proximal surface of the maxillary first molar to the palatal plane }[6,9,19]\end{array}$ \\
\hline Ratio $\left(A^{\prime} \sigma^{\prime} / A^{\prime} P^{\prime}\right)$ & The ratio of the anterior maxillary base length $A^{\prime} \sigma^{\prime}$ to the maxillary base length $A^{\prime} P^{\prime}\left(A^{\prime} \sigma^{\prime} / A^{\prime} P^{\prime}\right)[6,9,19]$ \\
\hline Overbite & $\begin{array}{l}\text { The overbite in millimeters is the distance between incisal edge of maxillary and mandibular central incisor, } \\
\text { perpendicular to occlusal plane [20] }\end{array}$ \\
\hline $\begin{array}{l}\text { Lower anterior facial } \\
\text { height (LAFH) }\end{array}$ & The length in millimeters of a line between points anterior nasal spine (ANS) and mental (Me) [21] \\
\hline $\begin{array}{l}\text { Ratio facial height } \\
(\mathrm{S}-\mathrm{Go} / \mathrm{N}-\mathrm{Me} \times 100)\end{array}$ & The ratio of posterior facial height and anterior facial height [22] \\
\hline
\end{tabular}

o Open bite class III group without maxillary posterior discrepancy (OBCIIIG-WPD) $(n=8)$ : the same with the OBCIIIG-PD, but without posterior discrepancy

When both cephalometric methods (ANB and APDI) to diagnose sagittal skeletal facial growth pattern did not agree an additional evaluation that included the analysis of skeletal facial profile (sagittal relationship of the points $\mathrm{N}, \mathrm{A}$, and $\mathrm{Pg}$ ), overjet, anteroposterior malocclusion, and soft profile convexity was considered before making a decision to which sagittal malocclusion group to assign any included case. All cephalometric radiographs were evaluated randomly.

\section{Maxillary posterior dentoalveolar discrepancy (MPDD)}

The dichotomous primary diagnosis of maxillary posterior discrepancy was made through radiographic evaluation by two calibrated examiners (LEAG, AADC). When the eruption of the maxillary third molar was apparently blocked by the presence of the erupted second, a maxillary posterior discrepancy was deemed present (Figs. 1 and 2).

In addition, for statistical analysis purposes, the ratio of the anterior maxillary base length $A^{\prime} 6^{\prime}$ to the maxillary base length $\mathrm{A}^{\prime} \mathrm{P}^{\prime}$ ( $\left.\mathrm{A}^{\prime} 6 / \mathrm{A}^{\prime} \mathrm{P}^{\prime}\right)$ was also calculated as a continuous variable that reflects maxillary posterior discrepancy (Fig. 3, Table 2). If the radio of the anterior maxillary base length $A^{\prime}{ }^{\prime}$ ' to the maxillary base length $\mathrm{A}^{\prime} \mathrm{P}^{\prime}\left(\mathrm{A}^{\prime} 6 / \mathrm{A}^{\prime} \mathrm{P}^{\prime}\right)$ was greater than 0.46 , then a maxillary posterior discrepancy was suggested $[6,9,19]$

\section{Maxillary molar sagittal angulation}

The sagittal angulations of maxillary first and second molars were measured by the angle formed by the molar axis (intercuspid groove-root bifurcation) and the palatal plane (Fig. 4).

\section{Statistical analysis}

All statistical analyses were performed using SPSS Ver.22 for Windows (IBM SPSS, Chicago, IL, USA). Data distribution normality was according to Shapiro- 
Table 3 Sample characteristics by facial growth pattern and maxillary posterior dentoalveolar discrepancy

\begin{tabular}{|c|c|c|c|c|c|c|}
\hline Measurement & Group & Mean & SD & Group & Mean & SD \\
\hline SNA & OBCIG-PD & $81.17^{*}$ & 2.89 & OBCIG-WPD & $84.54^{*}$ & 4.82 \\
\hline SNB & & 78.65 & 3.35 & & 81.03 & 4.45 \\
\hline ANB & & 2.54 & 1.20 & & 3.47 & 1.41 \\
\hline APDI & & 83.45 & 2.93 & & 81.95 & 2.26 \\
\hline FMP & & 30.48 & 2.70 & & 31.15 & 3.11 \\
\hline$A^{\prime} P^{\prime}$ & & $42.45^{*}$ & 2.89 & & $47.07^{*}$ & 3.10 \\
\hline$A^{\prime} \sigma^{\prime}$ & & 21.48 & 2.16 & & 20.66 & 2.71 \\
\hline Ratio $\left(A^{\prime} \sigma^{\prime} / A^{\prime} P^{\prime}\right)$ & & $0.50^{*}$ & 0.04 & & $0.44^{*}$ & 0.03 \\
\hline ODI & & 64.70 & 5.01 & & 68.19 & 5.60 \\
\hline Overbite & & -1.58 & 1.07 & & -2.50 & 1.52 \\
\hline Lower anterior facial height & & 67.99 & 4.88 & & 69.31 & 3.85 \\
\hline Ratio facial height & & 60.73 & 3.04 & & 62.50 & 3.22 \\
\hline SNA & OBCIIG-PD & 80.97 & 3.09 & OBCIIG-WPD & 82.51 & 2.79 \\
\hline SNB & & 74.54 & 2.90 & & 75.83 & 2.99 \\
\hline ANB & & 6.42 & 1.44 & & 6.68 & 1.24 \\
\hline APDI & & 74.06 & 3.37 & & 75.41 & 3.20 \\
\hline FMP & & 34.93 & 4.84 & & 34.02 & 4.28 \\
\hline$A^{\prime} P^{\prime}$ & & 43.62 & 3.63 & & 45.96 & 2.72 \\
\hline$A^{\prime} \sigma^{\prime}$ & & $23.02^{*}$ & 2.68 & & $21.23^{*}$ & 2.77 \\
\hline Ratio $\left(A^{\prime} \sigma^{\prime} / A^{\prime} P^{\prime}\right)$ & & $0.52^{*}$ & 0.04 & & $0.46^{*}$ & 0.05 \\
\hline ODI & & 70.39 & 5.14 & & 71.56 & 5.95 \\
\hline Overbite & & -2.25 & 1.56 & & -2.99 & 1.29 \\
\hline Lower anterior facial height & & 70.54 & 5.69 & & 73.44 & 5.12 \\
\hline Ratio facial height & & 58.50 & 3.41 & & 59.70 & 3.23 \\
\hline SNA & OBCIIIG-PD & $81.84^{*}$ & 3.27 & OBCIIIG-WPD & $78.22^{*}$ & 2.31 \\
\hline SNB & & $83.45^{*}$ & 4.16 & & $80.14^{*}$ & 1.90 \\
\hline ANB & & -1.61 & 1.36 & & -1.92 & 1.53 \\
\hline APDI & & $91.51^{*}$ & 4.48 & & $87.67^{*}$ & 1.68 \\
\hline FMP & & 31.91 & 3.60 & & 29.21 & 3.36 \\
\hline$A^{\prime} P^{\prime}$ & & 43.88 & 5.00 & & 44.06 & 4.32 \\
\hline$A^{\prime} 6^{\prime}$ & & 20.68 & 2.18 & & 19.71 & 2.12 \\
\hline Ratio $\left(A^{\prime} \sigma^{\prime} / A^{\prime} P^{\prime}\right)$ & & $0.48^{*}$ & 0.06 & & $0.44^{*}$ & 0.05 \\
\hline ODI & & $56.30^{*}$ & 4.55 & & $62.99^{*}$ & 1.11 \\
\hline Overbite & & -1.97 & 1.67 & & -1.78 & 1.54 \\
\hline Lower anterior facial height & & $70.37^{*}$ & 4.18 & & $74.27^{*}$ & 2.55 \\
\hline Ratio facial height & & 59.84 & 2.36 & & 60.52 & 1.65 \\
\hline
\end{tabular}

*Significant based on Independent $T$ test

Wilk tests. An independent $T$ test was performed to determine differences between two groups classified by the MPDD condition (present or absent) and sagittal malocclusion. Statistical significance was set at $p<0.05$. A principal component analysis (PCA) was used to reduce the number of variables considered during the multivariate analysis. Finally, a multivariate analysis
(MANCOVA) test was applied considering the effect of $\mathrm{SNB}, \mathrm{ANB}, \mathrm{APDI}, \mathrm{A}^{\prime} \mathrm{P}^{\prime}$, ratio $\left(\mathrm{A}^{\prime} 6^{\prime} / \mathrm{A}^{\prime} \mathrm{P}^{\prime}\right)$, overbite, lower anterior facial height, ratio facial height, maxillary posterior discrepancy, and sex (reduced by the PCA from the initial cephalometric variables) on the molar sagittal angulations (outcome variable). Statistical significance was set at $p<0.05$ for all the tests. 


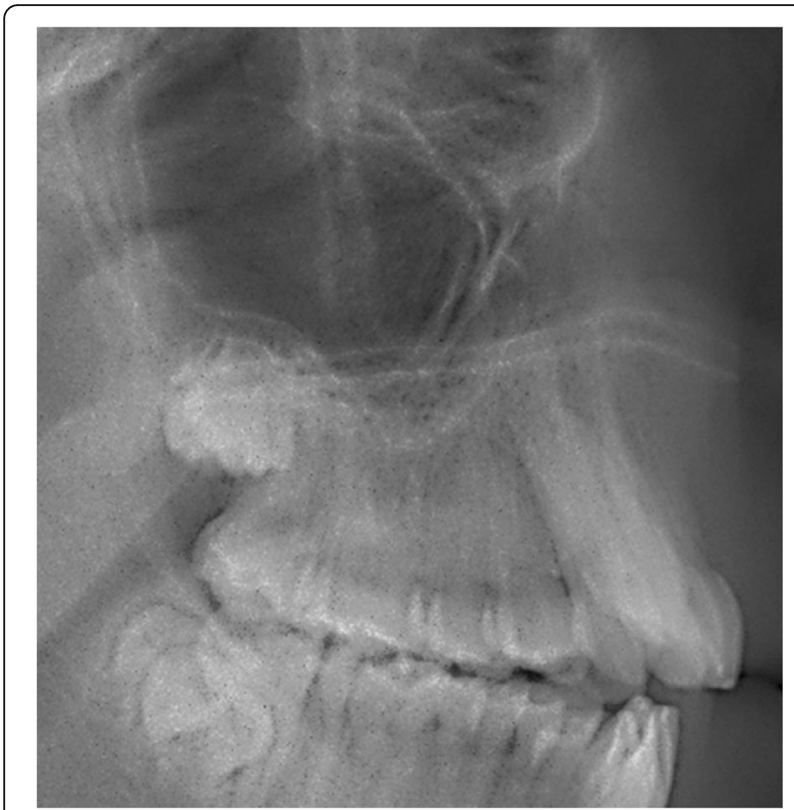

Fig. 1 Example of MPDD. The third molar was potentially blocked by the presence of the erupted second molar

\section{Results}

\section{Reliability}

Inter and intra-examiner reliability was assessed with the intra-class correlation coefficient (ICC). All cephalometric values were greater than 0.979 (CI $95 \% 0.954-0.999$ ). In addition, the Dahlberg error was less than $1^{\circ}$ for all angular measurements and $1 \mathrm{~mm}$ for all lineal measurements. All the cephalometric tracings were made with at least a

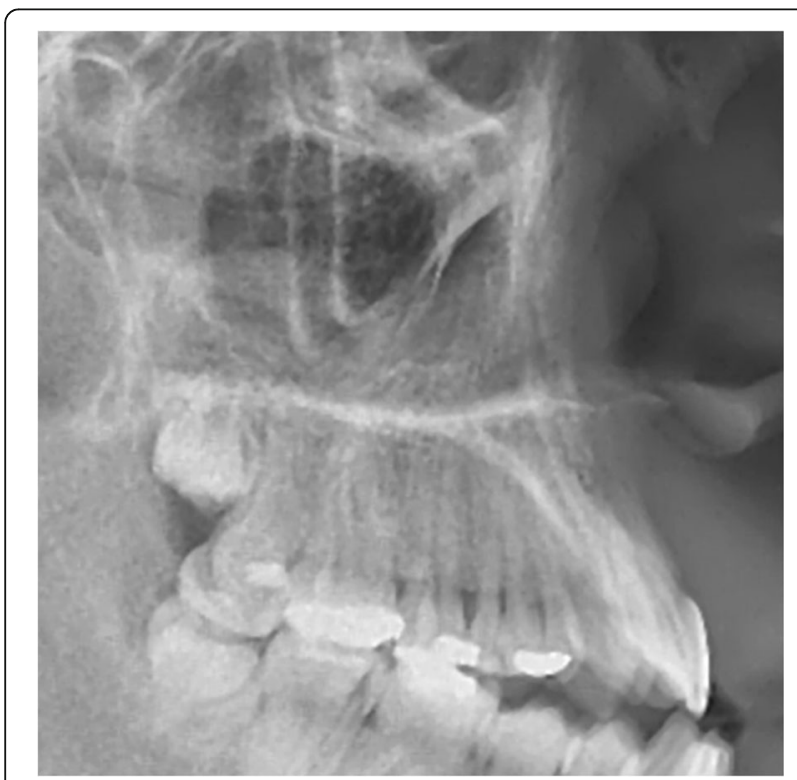

Fig. 2 Example of MPDD. The third molar was potentially blocked by the presence of the erupted second molar

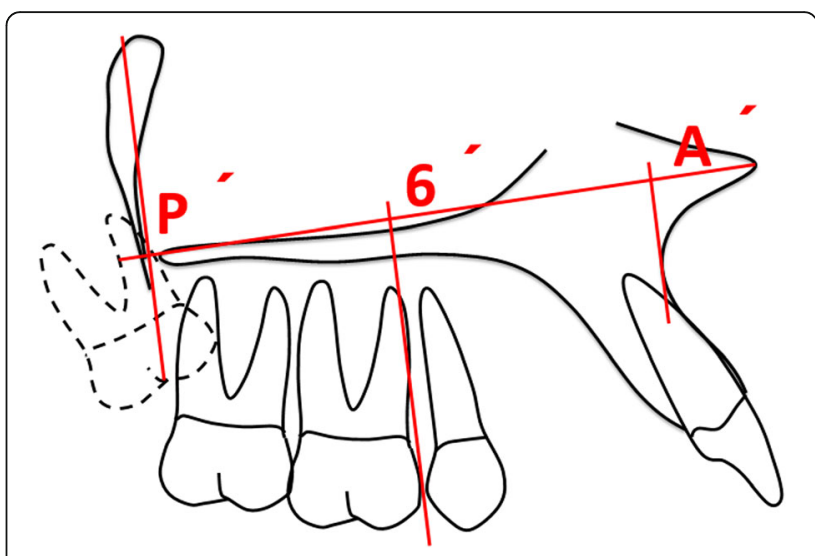

Fig. 3 MPDD evaluated by the ratio of the anterior maxillary base length $A^{\prime} \sigma^{\prime}$ to the maxillary base length $A^{\prime} P^{\prime}\left(A^{\prime} \sigma^{\prime} / A^{\prime} P^{\prime}\right)$

1-month interval between them and were performed by the same two different examiners.

\section{Outcome variables}

Table 3 shows the characteristics of the six groups by skeletal facial growth pattern and maxillary posterior discrepancy.

Descriptive statistics of the outcome variables can be found in Table 4. The maxillary first and second molar angulations in individuals with maxillary posterior discrepancy had a major distal crown tipping. The maxillary first molar angulation in the OBCIG-PD was $79.74^{\circ}$ $\pm 4.69^{\circ}$ and OBCIG-WPD was $88.41^{\circ} \pm 4.19^{\circ}(p<0.001)$, in the OBCIIG-PD was $74.17^{\circ} \pm 6.15^{\circ}$ and OBCIIG-WPD was $83.67^{\circ} \pm 5.55^{\circ}(p<0.001)$, and in the OBCIIIG-PD was $82.85^{\circ} \pm 5.50^{\circ}$ and OBCIIIG-WPD was $89.58^{\circ} \pm 1.94^{\circ}$ $(p=0.004)$. The maxillary second molar angulation in the OBCIG-PD was $71.04^{\circ} \pm 4.99^{\circ}$ and OBCIG-WPD was $82.94^{\circ} \pm 7.75^{\circ}(p<0.001)$, in the OBCIIG-PD was $61.98 \pm$ $7.80^{\circ}$ and OBCIIG-WPD was $79.27^{\circ} \pm 7.74^{\circ} \quad(p<0.001)$, and in the OBCIIIG-PD was $71.39^{\circ} \pm 7.25^{\circ}$ and OBCIIIG-WPD was $85.59^{\circ} \pm 1.71^{\circ}(p<0.001)$.

For the final analysis, the sample was separated into two groups according to MPDD (present $=50$, absent $=40$ ),

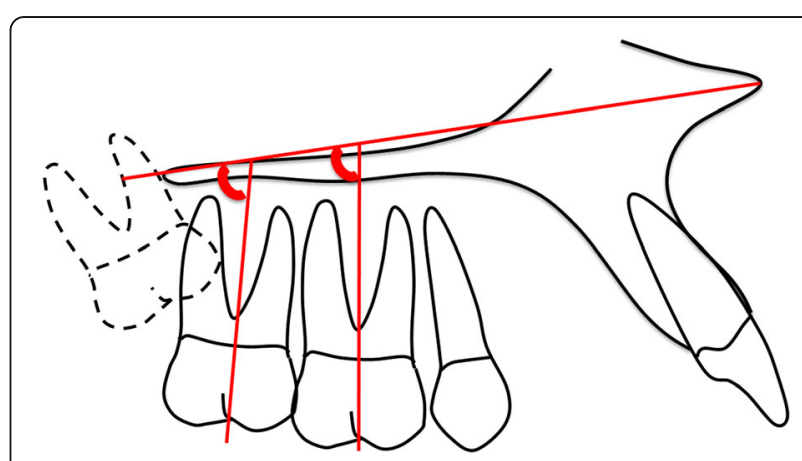

Fig. 4 Evaluation of molar sagittal angulations 
Table 4 Maxillary molar angulation according to maxillary posterior dentoalveolar discrepancy and facial growth pattern

\begin{tabular}{|c|c|c|c|c|c|c|}
\hline Measurement & Group & Mean & SD & Min & Max & $p$ \\
\hline \multirow[t]{6}{*}{ Maxillary first molar angulation } & OBCIG-PD & 79.74 & 4.69 & 73.00 & 89.39 & $<0.001^{*}$ \\
\hline & OBCIG-WPD & 88.41 & 4.19 & 80.92 & 92.85 & \\
\hline & OBCIIG-PD & 74.17 & 6.15 & 64.42 & 86.95 & $<0.001^{*}$ \\
\hline & OBCIIG-WPD & 83.67 & 5.55 & 72.65 & 92.35 & \\
\hline & OBCIIIG-PD & 82.85 & 5.50 & 75.58 & 95.10 & $0.004^{*}$ \\
\hline & OBCIIIG-WPD & 89.58 & 1.94 & 86.99 & 92.93 & \\
\hline \multirow[t]{6}{*}{ Maxillary second molar angulation } & OBCIG-PD & 71.04 & 4.99 & 59.22 & 78.79 & $<0.001^{*}$ \\
\hline & OBCIG-WPD & 82.94 & 7.75 & 64.24 & 90.06 & \\
\hline & OBCIIG-PD & 61.98 & 7.80 & 48.45 & 74.49 & $<0.001^{*}$ \\
\hline & OBCIIG-WPD & 79.27 & 7.74 & 62.16 & 94.56 & \\
\hline & OBCIIIG-PD & 71.39 & 7.25 & 59.27 & 86.07 & $<0.001^{*}$ \\
\hline & OBCIIIG-WPD & 85.59 & 1.71 & 83.10 & 88.36 & \\
\hline
\end{tabular}

*Significant based on $T$ Test

OBCIG open bite class I group, OBCIIG open bite class II group, OBCIIIG open bite class III group, PD posterior discrepancy, WPD without posterior discrepancy

trying to know the influence of MPDD in all types of malocclusion with open bite on the angulation of the upper molars. We also found significant differences between the two groups, $p<0.001$ (Table 5).

Through a PCA (Table 6), it was determined that ANB, FMP, and ODI, as well as SNA, and $\mathrm{A}^{\prime} \mathrm{P}^{\prime}$, equally $\mathrm{A}^{\prime} 6^{\prime}$, and ratio $\left(\mathrm{A}^{\prime} 6^{\prime} / \mathrm{A}^{\prime} \mathrm{P}^{\prime}\right)$ were significantly associated in this sample. $\mathrm{SNB}, \mathrm{ANB}, \mathrm{APDI}, \mathrm{A}^{\prime} \mathrm{P}^{\prime}$, ratio $\left(\mathrm{A}^{\prime} 6^{\prime} / \mathrm{A}^{\prime} \mathrm{P}^{\prime}\right)$, overbite, lower anterior facial height, ratio facial height maxillary posterior discrepancy, and sex were obtained after the reduction of the number of variables considered and were used in the MANCOVA. Significance was only found for maxillary posterior discrepancy $(p<0.001)$, APDI $(p=0.001)$, and ratio $\left(\mathrm{A}^{\prime} 6^{\prime} / \mathrm{A}^{\prime} \mathrm{P}^{\prime}\right)(p=0.026)$ for maxillary first molar angulation and APDI $(p=0.011)$ and maxillary posterior discrepancy $(p<0.001)$ for maxillary second molar angulation (Table 7).

\section{Discussion}

The purpose of this study was to determine the effect of MPDD on the sagittal angulation of maxillary molars in skeletal open bite subjects. Overall, it was found that MPDD was associated with a significant mesial angulation of the second and first molar roots with a concurrent simultaneous distal angulation of the associated crowns. The findings are clinically relevant as they allow clinicians to consider these associations when facing patients with a potential MPDD. Their treatment decisions could be affected based on the degree of third molar angulation and how the erupted first and second molars are distally angulated in such cases. Distal molar movement in class II malocclusions should be careful in such scenario as this type of movements tends to distally angulate molar crowns. The method utilized to diagnose maxillary posterior discrepancy used a radiographic visual assessment by two calibrated examiners (LEAG, AADC), where the sagittal maxillary length and the portrayed trajectory of eruption of the third molars were considered. An unfavorable maxillary third molar eruption angulation would likely imply impaction (Figs. 1 and 2). In the literature, it has been proposed that maxillary posterior discrepancy should be determined by the

Table 5 Maxillary molar angulation according to maxillary posterior dentoalveolar discrepancy

\begin{tabular}{|c|c|c|c|c|c|c|c|c|}
\hline \multirow[t]{2}{*}{ Measurement } & \multirow[t]{2}{*}{ Group } & \multirow[t]{2}{*}{ Number } & \multirow[t]{2}{*}{ Mean } & \multirow[t]{2}{*}{ SD } & \multirow[t]{2}{*}{ Mean difference } & \multicolumn{2}{|c|}{$\begin{array}{l}\text { Confidence interval } \\
95 \%\end{array}$} & \multirow[t]{2}{*}{$p$} \\
\hline & & & & & & Lower limit & Upper limit & \\
\hline \multirow[t]{2}{*}{$\begin{array}{l}\text { Maxillary first } \\
\text { molar angulation }\end{array}$} & $\begin{array}{l}\text { With maxillary posterior dentoalveolar } \\
\text { discrepancy }\end{array}$ & 50 & 78.43 & 6.46 & 7.61 & 5.07 & 10.13 & $<0.001^{*}$ \\
\hline & Without maxillary posterior dentoalveolar discrepancy & 40 & 86.04 & 5.33 & & & & \\
\hline \multirow[t]{2}{*}{$\begin{array}{l}\text { Maxillary second } \\
\text { molar angulation }\end{array}$} & $\begin{array}{l}\text { With maxillary posterior dentoalveolar } \\
\text { discrepancy }\end{array}$ & 50 & 67.69 & 8.01 & 13.76 & 10.51 & 17.01 & $<0.001^{*}$ \\
\hline & $\begin{array}{l}\text { Without maxillary posterior dentoalveolar } \\
\text { discrepancy }\end{array}$ & 40 & 81.45 & 7.31 & & & & \\
\hline
\end{tabular}


Table 6 Principal component analysis to reduce the number of variables under study

\begin{tabular}{lrrrr}
\hline Variables & \multicolumn{4}{l}{ Component } \\
\cline { 2 - 5 } & \multicolumn{1}{c}{2} & \multicolumn{1}{l}{3} & \multicolumn{1}{c}{4} \\
\hline SNA & -0.11 & $0.79^{\mathrm{a}}$ & 0.09 & 0.11 \\
SNB & -0.80 & 0.47 & 0.24 & -0.03 \\
ANB & $0.89^{\mathrm{a}}$ & 0.15 & -0.21 & 0.15 \\
APDI & -0.91 & 0.06 & 0.14 & -0.15 \\
FMP & $0.62^{\mathrm{a}}$ & -0.03 & 0.43 & -0.37 \\
A'P' $^{\prime}$ & 0.17 & $0.77^{\mathrm{a}}$ & -0.10 & -0.27 \\
A'6 $^{\prime}$ & 0.41 & 0.47 & $0.59^{\mathrm{a}}$ & 0.34 \\
Ratio & 0.27 & -0.07 & $0.70^{\mathrm{a}}$ & 0.59 \\
ODI & $0.59^{\mathrm{a}}$ & 0.18 & -0.58 & 0.37 \\
Overbite & -0.27 & -0.46 & 0.16 & 0.39 \\
Lower anterior facial height & -0.40 & 0.16 & 0.24 & -0.58 \\
Ratio facial height & -0.42 & 0.47 & -0.32 & 0.44 \\
\hline aRelated & & & &
\end{tabular}

Related

Table 7 MANCOVA assessing maxillary first and second molar angulations based in fixed factors and co-variables

\begin{tabular}{|c|c|c|}
\hline Dependent variable & Fixed factors and co-variables & $p$ \\
\hline \multirow{12}{*}{$\begin{array}{l}\text { Maxillary first molar } \\
\text { angulation }\end{array}$} & Corrected model & $<0.001^{*}$ \\
\hline & Intercept & $0.025^{*}$ \\
\hline & SNB & 0.200 \\
\hline & ANB & 0.971 \\
\hline & APDI & $0.001^{*}$ \\
\hline & $A^{\prime} P^{\prime}$ & 0.061 \\
\hline & Ratio $\left(A^{\prime} \sigma^{\prime} / A^{\prime} P^{\prime}\right)$ & $0.026^{*}$ \\
\hline & Overbite & 0.341 \\
\hline & Lower anterior facial height & 0.587 \\
\hline & Ratio facial height & 0.207 \\
\hline & Maxillary posterior discrepancy & $<0.001^{*}$ \\
\hline & Sex & 0.292 \\
\hline \multirow{12}{*}{$\begin{array}{l}\text { Maxillary second } \\
\text { molar angulation }\end{array}$} & Corrected model & $<0.001^{*}$ \\
\hline & Intercept & 0.824 \\
\hline & SNB & 0.613 \\
\hline & ANB & 0.714 \\
\hline & APDI & $0.011^{*}$ \\
\hline & $A^{\prime} P^{\prime}$ & 0.576 \\
\hline & Ratio $\left(A^{\prime} \sigma^{\prime} / A^{\prime} P^{\prime}\right)$ & 0.881 \\
\hline & Overbite & 0.229 \\
\hline & Lower anterior facial height & 0.652 \\
\hline & Ratio facial height & 0.238 \\
\hline & Maxillary posterior discrepancy & $<0.001^{*}$ \\
\hline & Sex & 0.777 \\
\hline
\end{tabular}

*Significant based on MANCOVA test ratio between the space from point $\mathrm{A}^{\prime}$ to mesial of the maxillary first molar, in relation to the space from point $\mathrm{A}^{\prime}$ to the most posterior point of the maxillary tuberosity $[6,9,19]$. When this ratio is increased, the chances of third molars having space for their eruption are diminished (Fig. 3).

The expected results, based on Kim [8] and Sato [9] hypothesis, were that there should be an increase in the mesial inclination of maxillary first and second molars (involving their crowns) that could promote posterior teeth interferences and therefore create a potential open bite scenario. However, the results of the current study suggested that maxillary molars showed more distally inclined crowns in the posterior discrepancy group. All the groups with posterior discrepancy showed significantly more distal molar crown angulation. This phenomenon supports the second hypothesis that the pressure from the erupting maxillary third molar against the anteriorly positioned molars may generate a major mesial displacement of the second and first molars roots with a concurrent simultaneous distal angulation of the associated crowns. These findings are in concordance with previous findings [1] where impacted third molars were observed to produce a distal angulation effect on the adjacent molars (involving their crowns) in subjects without open bite. Similar findings were observed in other studies $[4,23]$ showing that in high-angle cases, a greater degree of distal angulation of first molars was found. The latter suggested natural dentoalveolar compensation as potential explanation for the results.

\section{Limitations}

In this study, a maxillary posterior dentoalveolar discrepancy (defined in this study as an apparent lack of space for a complete maxillary third molar eruption) could be considered equivalent to maxillary third molar impaction.

A longitudinal cohort design would generate stronger data to support or refute the evaluated hypothesis and could use CBCT if possible, trying to avoid the superimpositions, although in this paper were excluded radiographs that showed evidently this problem.

Since open bite individuals without maxillary posterior discrepancy could have unerupted third molars with available space and good eruption pattern or third molars in occlusion, ideally, a study considering the maxillary molars inclination using open bite individuals with posterior discrepancy and open bite individuals with fully erupted third molar should follow-up. Results of such studies may or not support this study's conclusion.

Previously, two studies $[1,24]$ used complete root formation with the highest part of third molar below the cervical line of second molar as a criterion for third molar impaction, but they do not consider the direction of eruption that is likely directly related to the impaction 
potential. In addition, the third molar's roots are not fully formed until 20 to 22 years of age [24]. Accordingly, third molar impaction could be over diagnosed when examining subjects younger than 20 years old. In the current study, the subjects were between 15 to 30 years old. This could be considered a weakness, but it was, at least partially, controlled considering the eruption trajectory of third molar crowns as an independent factor from complete root formation.

The association between the severity of maxillary molar crown distal inclination and the degree of MPDD was not evaluated in this study.

\section{Conclusions}

The maxillary posterior dentoalveolar discrepancy generates a major mesial displacement of the second and first molar roots with a concurrent simultaneous distal angulation of the associated crowns in individuals with skeletal open bite.

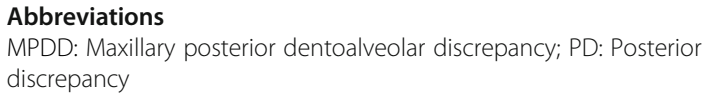

\section{Acknowledgements}

We would like to thank the Cientifica del Sur University, where the measurements were performed.

\section{Authors' contributions}

LEAG participated in the study conception, the data collection, the manuscript formatting, and the statistical analysis. AADC participated in the study conception, the data collection, and the manuscript formatting. CFM participated in the manuscript formatting, the statistical analysis, and the data interpretation. All authors read and approved the final manuscript.

\section{Competing interests}

The authors declare that they have no competing interests.

\section{Consent for publication}

Not applicable.

\section{Ethics approval}

Approved by the ethical committee of the School of Dentistry, Universidad Científica del Sur, Lima, Perú

\section{Author details}

${ }^{1}$ Division of Orthodontics, Faculty of Dentistry, Universidad Científica del Sur - UCSUR, Calle Los Girasoles \# 194, Dpto. \# 302, Urb. Residencial Los Ingenieros de Valle Hermoso, Santiago de Surco, Lima, Perú. ${ }^{2}$ Department of Orthodontics, Bauru Dental School, University of São Paulo, Bauru, Brazil.

${ }^{3}$ Faculty of Medicine and Dentistry, University of Alberta, Edmonton, Alberta, Canada.

Received: 2 August 2016 Accepted: 19 September 2016 Published online: 01 November 2016

\section{References}

1. Badawi Fayad J, Levy JC, Yazbeck C, Cavezian R, Cabanis EA. Eruption of third molars: relationship to inclination of adjacent molars. Am J Orthod Dentofacial Orthop. 2004;125:200-2.

2. Stanaityté R, Trakiniené G, Gervickas A. Lower dental arch changes after bilateral third molar removal. Stomatologija. 2014;16:31-6.

3. Liao $\mathrm{CH}$, Yang P, Zhao ZH, Zhao MY. Study on the posterior teeth mesiodistal tipping degree of normal occlusion subjects among different facial growth patterns. West China J Stomatol. 2010;28:374-7.
4. Su H, Han B, Li S, Na B, Ma W, Xu TM. Compensation trends of the angulation of first molars: retrospective study of 1403 malocclusion cases. Int J Oral Sci. 2014;6:175-81.

5. Merrifield LL, Klontz HA, Vaden JL. Differential diagnostic analysis system. Am J Orthod Dentofacial Orthop. 1994;106:641-8.

6. Sato S. Alteration of occlusal plane due to posterior discrepancy related to development of malocclusion-introduction to denture frame analysis. Bull Kanagawa Dent Coll. 1987;15:115-23.

7. Sato S, Takamoto K, Suzuki Y. Posterior discrepancy and development of skeletal class III malocclusion: its importance in orthodontic correction of skeletal class III malocclusions. Orthodontic Review. 1988:2:16-29.

8. Kim YH. Anterior openbite and its treatment with multiloop edgewise archwire. Angle Orthod. 1987:57:290-321.

9. Sato S. An approach to the treatment of malocclusion in consideration of dentofacial dynamics. Tokyo: Torin Books; 1991. In Japanese.

10. Kim YH, Han UK, Lim DD, Serraon ML. Stability of anterior openbite correction with multiloop edgewise archwire therapy: a cephalometric follow-up study. Am J Orthod Dentofacial Orthop. 2000;118:43-54.

11. Gavazzi M, De Angelis D, Blasi S, Pesce P, Lanteri V. Third molars and dental crowding: different opinions of orthodontists and oral surgeons among Italian practitioners. Progress in Orthodontics 2014, doi: 10.1186/s40510-014-0060-y

12. Costa MG, Pazzini CA, Pantuzo MC, Jorge ML, Marques LS. Is there justification for prophylactic extraction of third molars? A systematic review. Braz Oral Res. 2013;27:183-8.

13. Zawawi $\mathrm{KH}$, Melis M. The role of mandibular third molars on lower anterior teeth crowding and relapse after orthodontic treatment: a systematic review. Sci World J. 2014;2014:615429.

14. Stanaityté R, Trakiniene G, Gervickas A. Do wisdom teeth induce lower anterior teeth crowding? A systematic literature review. Stomatologija. 2014;16:15-8.

15. Arriola-Guillén LE, Aliaga-Del Castillo A, Pérez-Vargas LF, Flores-Mir C. Influence of maxillary posterior discrepancy on upper molar vertical position and facial vertical dimensions in subjects with or without skeletal open bite 2015. Eur J Orthod. 1-8, doi:10.1093/ejo/cjv067

16. Steiner C. Cephalometrics for you and me. Am J Orthod. 1953;39:729-55.

17. Kim YH, Vietas JJ. Anteroposterior dysplasia indicator: an adjunct to cephalometric differential diagnosis. Am J Orthod. 1978;73:619-33.

18. Kim YH. Overbite depth indicator with particular reference to anterior open-bite. Am J Orthod. 1974;65:586-611.

19. Celar AG, Freudenthaler JW, Celar RM, Jonke E, Schneider B. The denture frame analysis: an additional diagnostic tool. Eur J Orthod. 1998;20:579-87.

20. Janson G, Crepaldi MV, de Freitas KM, de Freitas MR, Janson W. Evaluation of anterior open-bite treatment with occlusal adjustment. Am J Orthod Dentofacial Orthop. 2008;134:10-1.

21. McNamara Jr JA. A method of cephalometric evaluation. Am J Orthod, 1984;86:449-69.

22. Jarabak JR, Fizzell JA. Technique and treatment with light wire edgewise appliances. Saint Louis: CV Mosby; 1972.

23. Chang $\mathrm{Yl}$, Moon SC. Cephalometric evaluation of the anterior open bite treatment. Am J Orthod Dentofacial Orthop. 1999;115:29-38.

24. Kim TW, Artun J, Behbehani F, Artese F. Prevalence of third molar impaction in orthodontic patients treated nonextraction and with extraction of 4 premolars. Am J Orthod Dentofacial Orthop. 2003;123:138-45.

\section{Submit your manuscript to a SpringerOpen ${ }^{\circ}$ journal and benefit from:}

- Convenient online submission

- Rigorous peer review

- Immediate publication on acceptance

- Open access: articles freely available online

- High visibility within the field

- Retaining the copyright to your article

Submit your next manuscript at $>$ springeropen.com 